\title{
Study on the Morphologies and Formational Mechanism of Poly(hydroxybutyrate-co-hydroxyvalerate) Ultrafine Fibers by Dry-Jet-Wet-Electrospinning
}

\author{
Shuqi Zhu, ${ }^{1}$ Hao Yu, ${ }^{2}$ Yanmo Chen, ${ }^{1}$ and Meifang $\mathrm{Zhu}^{2}$ \\ ${ }^{1}$ College of Material Science \& Engineering, Donghua University, Songjiang, Shanghai 201620, China \\ ${ }^{2}$ State Key Lab for Modification of Chemical Fibers and Polymer Materials, 2999 North Renmin Road, Songjiang, \\ Shanghai 201620, China \\ Correspondence should be addressed to Hao Yu, yuhao@dhu.edu.cn and Meifang Zhu, zhumf@dhu.edu.cn
}

Received 27 June 2012; Revised 3 October 2012; Accepted 3 October 2012

Academic Editor: Yanqiu Zhu

Copyright ( 2012 Shuqi Zhu et al. This is an open access article distributed under the Creative Commons Attribution License, which permits unrestricted use, distribution, and reproduction in any medium, provided the original work is properly cited.

\begin{abstract}
Dry-jet-wet-electrospinning (DJWE) was carried out to study the formational mechanism of poly(hydroxybutyrate-cohydroxyvalerate) electrospun fibers. Morphological comparison between normal electrospinning (NE) and DJWE was investigated. The results showed that jet could solidify quickly in DJWE to avoid bead collapse or fiber coherence. Jet structures could be maintained at very low collection distance. Beanpod-like beads, which were named as primary beads, could be seen at the boundary of stability and instability section and divided into spindle-like beads with longer collection distance. Bead-free electrospun fibers from DJWE had few bonding points among each other, and fast solidification and double-diffusion led to rough and shriveled fiber surface. DJWE mats were higher hydrophobic than that from NE due to more loose structure and higher surface porosity. Higher bead ratio on the surface and rounder bead structure resulted in higher hydrophobicity.
\end{abstract}

\section{Introduction}

Electrospinning was regarded as a very convenient and effective method for preparing nanofibers and ultrafine fibers, which could be used for filtration $[1,2]$, tissue engineering scaffolds [3-5], protective clothes [6, 7], carriers for enzymes $[8,9]$, sensors [10-12], and so forth. Many researchers focused on the theories and the phenomena of the electrospinning process [13-16]. However, there were some difficulties in studying the morphology at very low collection distance. For example, the transformation process of instability section, especially the deformation of beads, which was of great importance for understanding the formation of ultrafine fibers, could not be observed clearly by high-speed photography. Besides, as the solidification mechanism of the normal electrospun fibers was solvent volatilization, the jet near the needle contained a large amount of solvent and could not maintain the structures when collected on glass slides or aluminum foils. So the fiber collected at low distance always deformed or even collapsed on solid substrates and the exact morphology could not be observed.

Dry-jet-wet-electrospinning (DJWE) was one electrospinning method for producing fibers from nonvolatile solvent, such as room temperature ionic liquids $[17,18]$. It was also used for preparing aligned nanofiber yarns [19]. This method, though usually called wet electrospinning, actually had the similar fiber solidification mechanism with dry-jet-wet-spinning, only differed in driving force. Fibers were electrospun into the coagulation bath, with precipitant for polymers in it. In another word, the polymer could not be dissolved in the bath, whereas the solvent could. The fiber solidified by double-diffusion of the solvent and the bath liquid, which was much faster than volatilization mechanism in normal electrospinning (NE). So the morphology of the fiber could be kept even at a low collection distance.

Moreover, electrospun mat usually had higher hydrophobicity than solution cast film, due to higher surface roughness. And some works found that mats with beaded structures were higher hydrophobic, even superhydrophobic 
[20-23], though beaded structures were usually considered as defects in electrospinning. However, it was difficult to prepare mats with high bead density, for beads collapsed as a result of residue solvent.

In this work, poly(hydroxybutyrate-co-hydroxyvalerate) $(\mathrm{PHBV}) /$ chloroform electrospinning solution was used as a model $[23,24]$. PHBV was biosynthesized aliphatic copolyester, which varied with different morphologies. Its electrospun products were also used to study the morphologies and surface wettability $[25,26]$. Chloroform is volatile solvent but could not be removed completely at low collection distance. Ethanol was used as coagulation bath, because chloroform was soluble and PHBV was precipitated in it. The morphologies of beaded and bead-free electrospun mats produced by NE and DJWE were compared. Some new structures and phenomena could be seen in DJWE method, and theories on bead deformation process at very low collection distance were introduced. Finally, the wettability of all the electrospun mats prepared by NE and DJWE was compared using water contact angle.

\section{Experimental}

2.1. Materials. PHBV was kindly supplied by Ningbo Tianan Biomaterial Co. Ltd., $\mathrm{Mw}=3.0 \times 10^{5} \mathrm{~g} / \mathrm{mol}$ (measured by GPC), $\mathrm{HV}$ mol\% = 2\% (measured by ${ }^{1} \mathrm{H}$ NMR). Chloroform was purchased from Boer Chemical Reagent Co. Ltd. Anhydrous ethanol and ethyl acetate were purchased from Shanghai Chemical Reagent Co. Ltd. PHBV was Soxhlet extracted by chloroform at $80^{\circ} \mathrm{C}$ and then deposited with ethyl acetate. The deposition was filtrated and vacuum dried at $40^{\circ} \mathrm{C}$ for $12 \mathrm{~h}$, and pure PHBV was acquired.

2.2. Electrospinning Apparatus. The apparatus used in this research was shown in Figure 1. A PHD 22/2000 syringe pump (Harvard Apparatus, Inc.) was used to feed the solution. The PTFE tube connected the syringe with the stainless needle. The inner diameter of needle was about $0.8 \mathrm{~mm}$. The positive pole of the high voltage supply was connected to the needle, and the negative pole was connected to the iron plate under the coagulation bath and grounded. The liquid in the coagulation bath was anhydrous ethanol. And aluminum foil was used to collect fibers in NE.

2.3. Electrospinning. The PHBV/chloroform electrospinning solution was prepared as in Table 1 . The solution viscosity, conductivity, and surface tension were measured by $\mathrm{R} / \mathrm{S}$ Plus Rheometer (Brookfield, Inc.), EL30 conductivity meter (Mettler Toledo), and OCA40 video based contact angle measurement device (Dataphysics), respectively.

Electrospinng was carried out at room temperature $\left(20^{\circ} \mathrm{C}\right)$ and humidity of $60-70 \%$. The applied voltage between the needle and ground was $10 \mathrm{kV}$, and the feeding rate was $3 \mathrm{~mL} / \mathrm{h}$. The mats were collected on aluminum foil or in ethanol bath at various distances. All the mats were dried in the air at room temperature for $24 \mathrm{~h}$, and then vacuum dried for $12 \mathrm{~h}$. The morphology was observed by scanning electronic microscopy (SEM, JSM-5600LV, JEOL
Ltd.). The water contact angles were measured by OCA40 video based contact angle measurement instrument (Dataphysics).

\section{Results and Discussion}

3.1. Morphological Comparison of Beaded Electrospun Fibers by DJWE and NE. Fibers electrospun from $6 \mathrm{wt} \% \mathrm{PHBV}$ solution by NE and DJWE at various distances varied considerably in morphology (Figure 2). The solution of that concentration had a jet of $3-5 \mathrm{~cm}$ stability section. If the jet was collected by NE, it could be observed that the jets did not solidify when they were collected on Al foil. And lower collection distance was used, more collapsed jets could be observed. So the detailed structure of the jet could be obtained if the jet was collected by NE. If the jet was collected by DJWE, it could be seen that all the fibers, no matter how long in distance the jet was collected, had original shape and clear boundary with each other. No collapsed or adhered fibers could be seen. When collected at $3 \mathrm{~cm}$, the jet was in the stability section, and thinned slowly and continuously. So the fiber diameter was large, and no beads or thin fibers could be seen. If the collection distance was $6 \mathrm{~cm}$, the jet had just entered the instability section, so the jet started to swing. Fibers having much lower diameters than the jet and beaded structures between two adjacent fibers appeared at this collection distance. It was interesting that the beads were beanpod-like, which had not reported yet. And compared to the spindle-like beads at longer distance, the beanpod-like beads were 2 times in volume, and had tendency to split into two spindle-like beads. It could be inferred that the spindlelike beads came from the splitting of beanpod-like beads. To distinguish the two different beads, the beanpod-like beads were named as primary beads, and spindle-like beans were named as secondary beans. Because of large residual solvent, the primary beads were easily collapsed in NE. Normally they could not be observed. When increasing the collection distance, the shape of the beads did not change again, and the fibers became longer but the diameter changed little, which was consistent with our previous work [27].

3.2. Bead Formation Mechanism at the Boundary of Stability and Instability Section. The beanpod-like beads were seldom reported in previous works, but they were a key to understand the deformation process of the jet during electrospinning at the boundary of stability and instability sections. When at the stability section, the jet diameter decreased slowly and continuously, containing a large amount of solvent. After entering the instability section, the jet whipped and swung. The defects of the jet were firstly stretched by the electrical field into thinner fibers, whereas the unstretched parts remained cylindrical because of viscosity. These cylindrical parts, with the central region shrinking slightly due to surface tension, became the primary beads. The fibers had faster solvent evaporation and solidified quickly as the result of large specific surface area than the beaded structures. Fast solidification and tensile strengthening made the fiber stronger. So when the 
TABLE 1: The components and parameters of electrospinning solutions.

\begin{tabular}{cccccccc}
\hline No. & $\begin{array}{c}\text { PHBV } \\
(\mathrm{g})\end{array}$ & $\begin{array}{c}\text { Concentration } \\
(\mathrm{wt} \%)\end{array}$ & $\begin{array}{c}\text { Chloroform } \\
(\mathrm{g})\end{array}$ & $\begin{array}{c}\text { Ethanol } \\
(\mathrm{g})\end{array}$ & $\begin{array}{c}\text { Viscosity* } \\
(\mathrm{Pa} \cdot \mathrm{s})\end{array}$ & $\begin{array}{c}\text { Conductivity } \\
(\mu \mathrm{S} / \mathrm{cm})\end{array}$ & $\begin{array}{c}\text { Surface tension } \\
(\mathrm{mN} / \mathrm{m})\end{array}$ \\
\hline 1 & 0.8 & 4 & 19.2 & 0 & 0.151 & Not detected $^{* *}$ \\
2 & 1.2 & 6 & 18.8 & 0 & 0.546 & Not detected $^{* *}$ \\
3 & 1.6 & 8 & 16.4 & 27.29 & 27.51 \\
\hline
\end{tabular}

${ }^{*}$ The viscosity was measured at shearing rate of $100 / \mathrm{s}$.

** The conductivity was lower than $0.001 \mu \mathrm{S} / \mathrm{cm}$ and could not be detected.

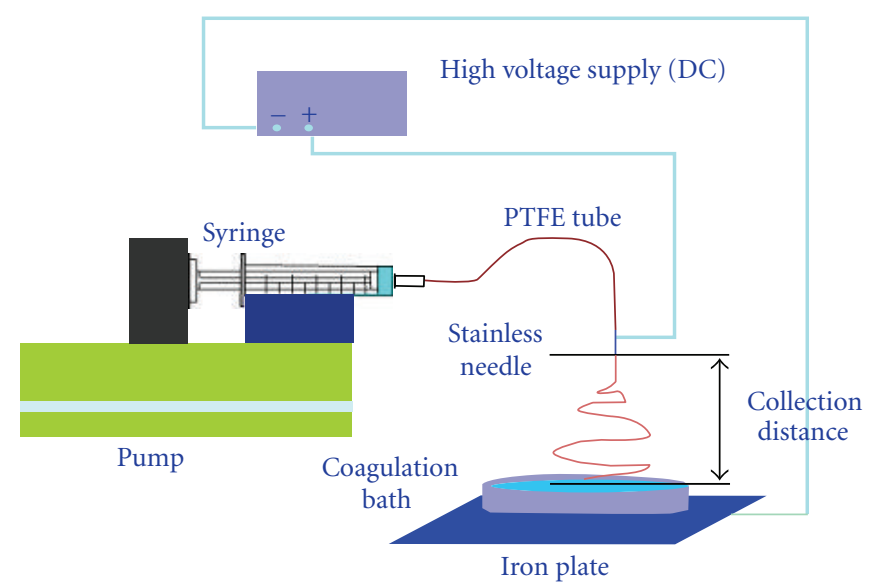

FIGURE 1: Illustration of the apparatus for dry-jet-wet-electrospinning.

thinner fibers had better strength than the primary beads, the beads would be deformed by the electric field force instead of fibers. Due to the effect of the electrical force and surface tension, the primary beads were stretched into two or more spindle-like beads. All the deformation process was illustrated in Figure 3. When further increasing the collection distance, the length of fibers between adjacent beads increased and beaded structures changed little except for the decreasing volume, which transformed into new fibers. But if the fiber strength was weaker than the primary beads strength, the fiber might be broken down, or secondary beads would not turn up. Then the primary beads contracted into spindle-like or spherical beads as a result of surface tension.

In further proof of this theory, the $4 \mathrm{wt} \% \mathrm{PHBV}$ solution was electrospun into ethanol bath and collected at $4 \mathrm{~cm}$ and $6 \mathrm{~cm}$. The jet collected at $4 \mathrm{~cm}$ obtained primary beads and very short fibers between adjacent beads (Figure 4(a)). Other than cylinder-like beads, the primary beads were spherical with diameter of $20 \mu \mathrm{m}$. The viscosity of $4 \mathrm{wt} \%$ solution was much lower than that of $6 \mathrm{wt} \%$. So the primary beads could not keep their structures when the surface tension acted on them. When collected at $6 \mathrm{~cm}$, the beads were slightly stretched but had similar diameters as that obtained at $4 \mathrm{~cm}$ (Figure 4(b)). Broken ends of fibers could be seen in the mat. The most likely reason was that the jet had such low polymer concentration. So the obtained fibers had poor mechanical properties. When the jet was stretched, the fiber was easily broken down, and the primary beads could not be stretched into secondary beads.
3.3. Morphological Comparison of Bead-Free Electrospun Fibers. $8 \mathrm{wt} \%$ PHBV solution with $10 \mathrm{wt} \%$ of ethanol could be electrospun into ultrafine PHBV fibers without beads, due to higher conductivity and viscosity than $6 \mathrm{wt} \% \mathrm{PHBV}$ solution (Table 1). The PHBV fiber prepared by NE did not solidify when collected and heavily cohered with each other because chloroform evaporated incompletely (Figure 5(a)). If the collection distance was increased to $12 \mathrm{~cm}$, chloroform further evaporated and the coherence alleviated, but there were still many bonds among fibers (Figure 5(b)). Due to slow evaporation of solvent, the fiber surface was smooth without pores. However, if the PHBV fiber was prepared by DJWE, the surface of fiber was rough and shriveled (Figure 5(c)). But the fibers were cylindrical with slightly rough surface if they were collected in the bath at $12 \mathrm{~cm}$ (Figure $5(\mathrm{~d})$ ). Both of the samples from DJWE showed few bond points and clear boundary for each fiber. The roughness and shrinkage of the fiber surface collected at $6 \mathrm{~cm}$ was a result of the fast solidification and double-diffusion of solvent and nonsolvent. When the jet was immersed into the bath, the surface was firstly solidified into shell structure to restrict the fiber external diameter. Then the solvent transferred towards the bath, while the nonsolvent had the opposite transference direction during the doublediffusion process. The core part of the fiber solidified at a relatively low rate and formed a compact structure, which led to the shrinkage of the surface during the process. If the collection distance increased, a large part of the solvent was removed by evaporation before fibers were immersed into bath. It was a relatively tempered solidification process, so 




(a1)

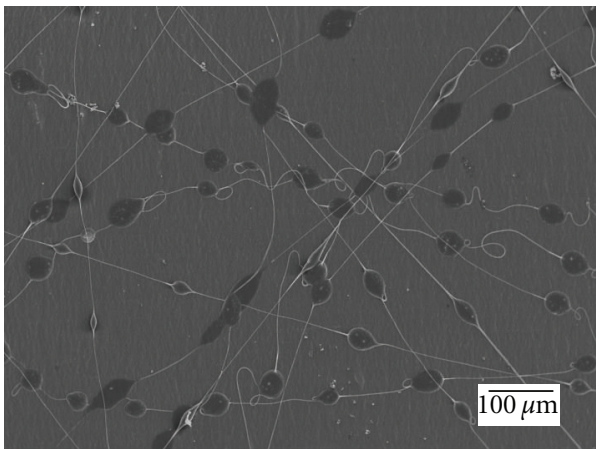

(a2)

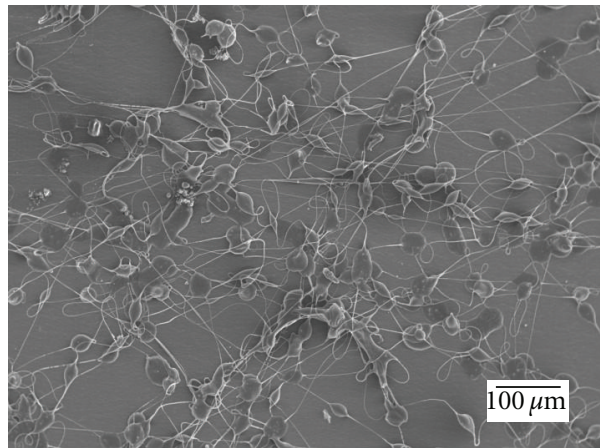

(a3)

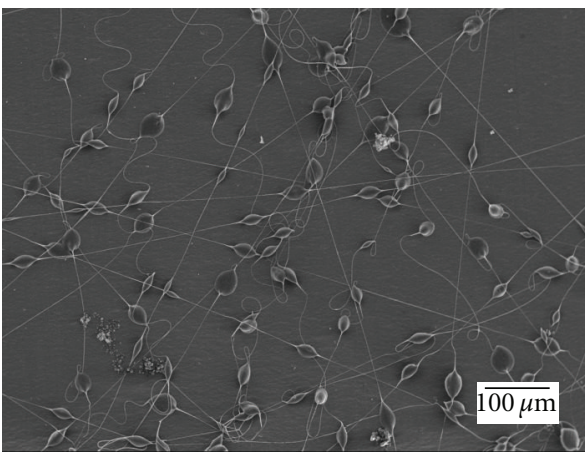

(a4)

(a)

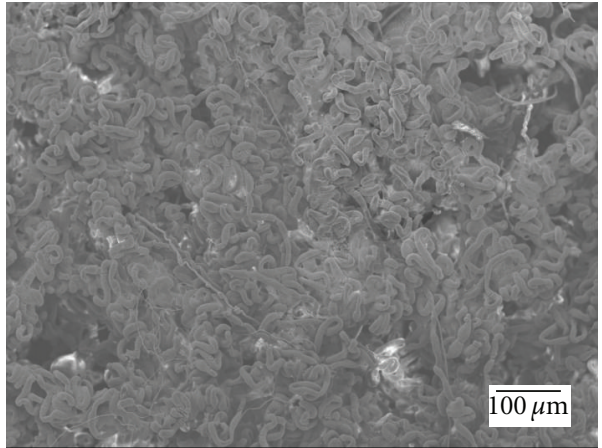

(b1)



(b2)

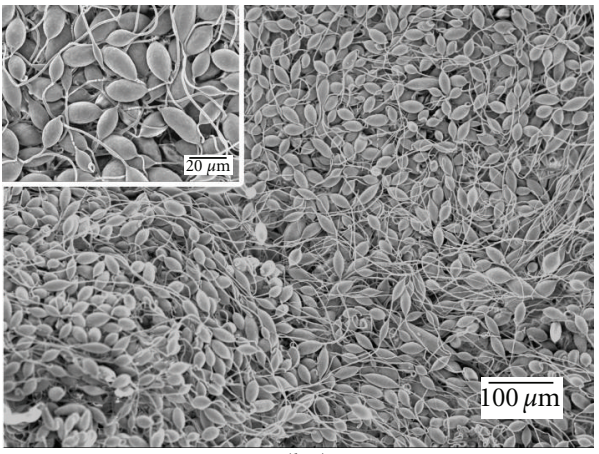

(b3)

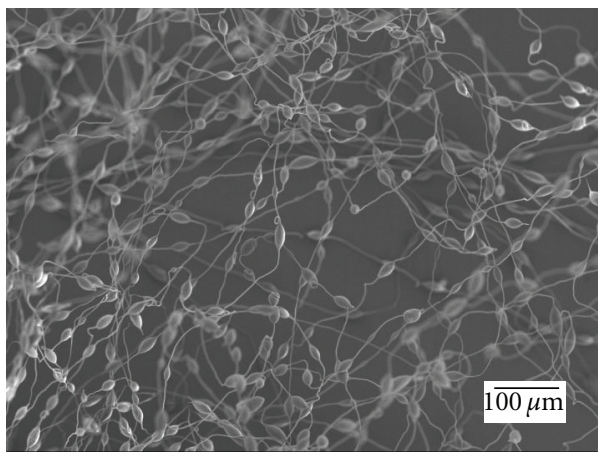

(b4)

(b)

Figure 2: Electrospun PHBV fiber prepared by NE (a) and DJWE (b). $1: 3 \mathrm{~cm} ; 2: 6 \mathrm{~cm} ; 3: 9 \mathrm{~cm} ; 4: 12 \mathrm{~cm}$.

the fiber kept cylindrical and the diameter decreased with the evaporation of chloroform. After immersed into the bath, though undergoing the similar process as collected at $6 \mathrm{~cm}$, the fiber's core part shrank little because of less residual solvent.
3.4. Wettability. The water contact angles of electrospun mats collected at different distances and substrates varied a lot due to the morphology (Figure 6). It could be concluded that beaded fiber mats prepared by DJWE from $6 \mathrm{wt} \% \mathrm{PHBV}$ solution had higher water contact angle than that prepared 


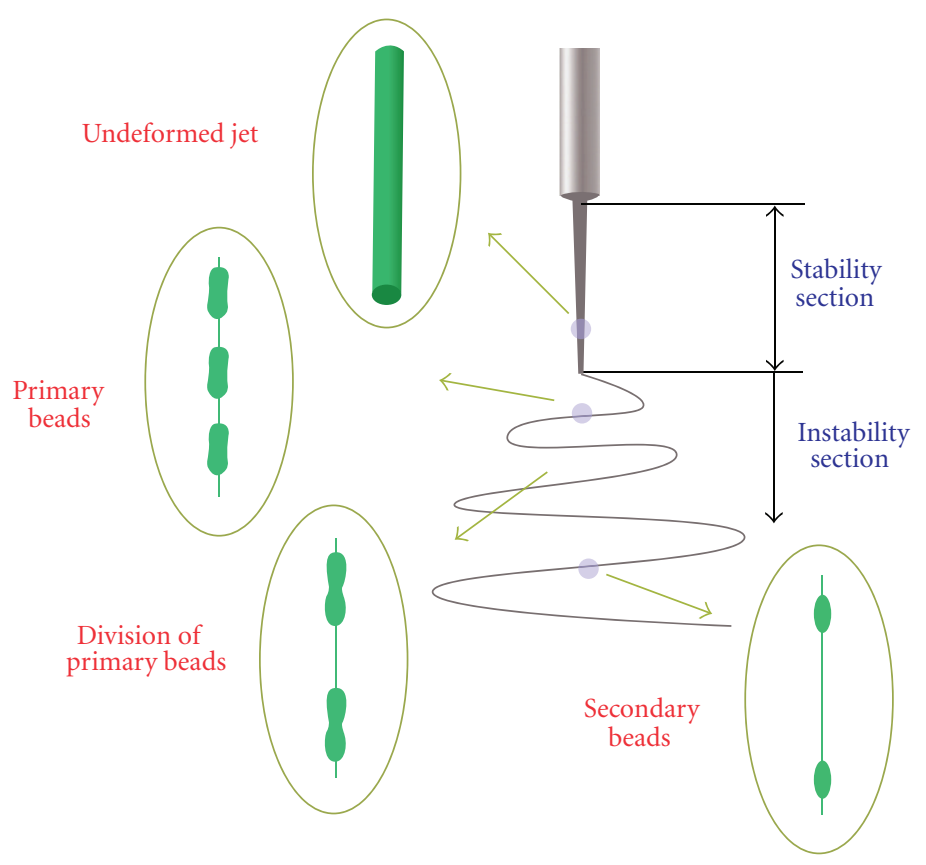

FIGURE 3: Mechanism of the PHBV beaded fiber formation at the boundary of stability and instability sections.

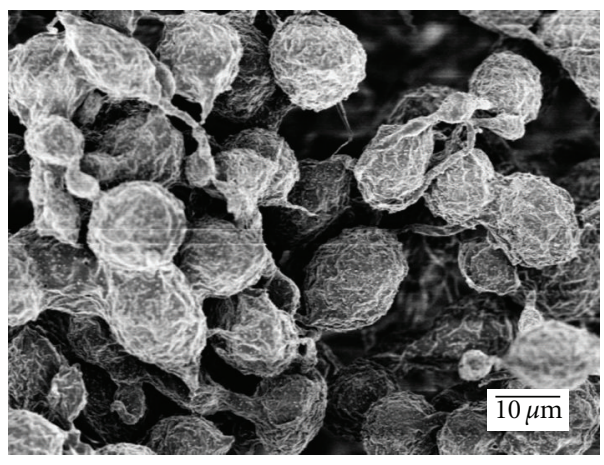

(a)

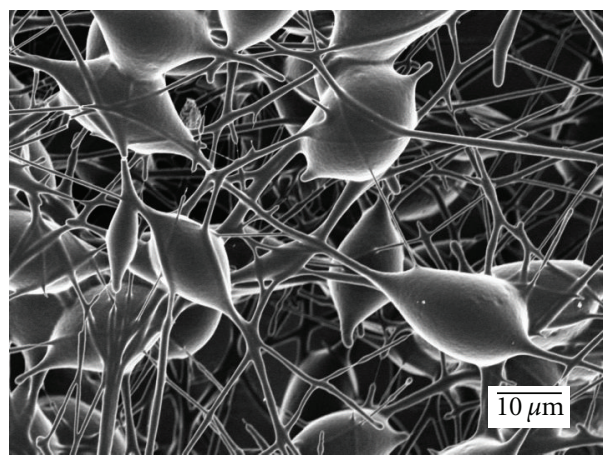

(b)

FiguRE 4: Beaded fibers prepared by DJWE of $4 \mathrm{wt} \%$ PHBV solution with collection distance of $4 \mathrm{~cm}$ (a) and $6 \mathrm{~cm}$ (b).

by normal electrospinning. Besides, mats with rounder beads and higher bead ratio had higher contact angle. According to the Cassie and Baxter's work [28], the apparent contact angle $\left(\theta^{\prime}\right)$ associated with the surface composition has the following relationship:

$$
\cos \theta^{\prime}=f_{1} \cos \theta_{1}+f_{2} \cos \theta_{2},
$$

where $f_{1}$ and $f_{2}$ are the fractions of the surface with contact angle of $\theta_{1}$ and $\theta_{2}$. If one component is air, whose contact angle was $180^{\circ}$, the equation can be written as follows:

$$
\cos \theta^{\prime}=f_{1} \cos \theta_{1}-f_{2} .
$$

It could be inferred from this equation that the composite surface containing larger air fraction $\left(f_{2}\right)$ had higher apparent contact angle $\left(\theta^{\prime}\right)$. Beaded fiber mats could create rougher surface which held more air and therefore, higher contact angle.
The wettability differed even widely for the $4 \mathrm{wt} \%$ PHBV solution prepared by DJWE and normal electrospinning with a collection distance of $4 \mathrm{~cm}$. During normal electrospinning, all the beads collapsed into flat sheets (Figure 7). Though with rather rough surface, the mat had even lower contact angle than solution cast film $\left(77^{\circ}\right)$. This might be due to the shallow surface pores which helped the water spreading. On the other hand, the mats prepared by DJWE had the highest contact angle $\left(142^{\circ}\right)$ (Figure 3(a)), as a result of high beads density and round beads with rough surface, which was $67^{\circ}$ higher than that of the solution cast film, and $72^{\circ}$ higher than that prepared by normal electrospinning. However, the mat was rather weak and brittle, because the beads, which were considered as defects of electrospun fibers, had bad mechanical properties.

For the beaded nanofiber mats from $6 \mathrm{wt} \%$ PHBV solution, there were similar trends (Figure 2). Because the beads and fibers did not cohere heavily, the mats could 


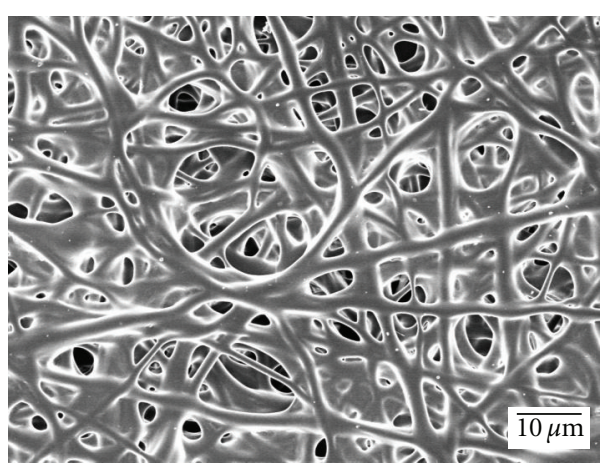

(a)



(c)

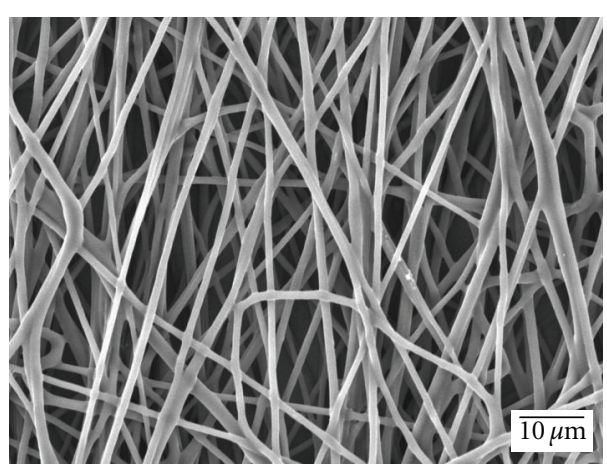

(b)

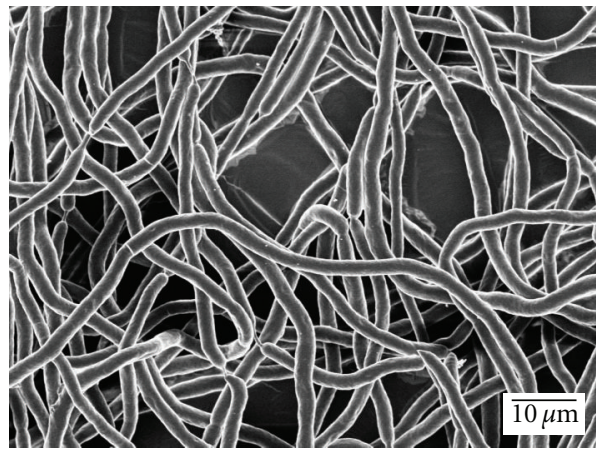

(d)

FIGURE 5: Morphologies of PHBV ultrafine fibers prepared by normal electrospinning (NE) (a, b) and dry-jet-wet-electrospinning (DJWE) (c, d). Collection distances were $6 \mathrm{~cm}$ for (a) and (c), $12 \mathrm{~cm}$ for (b) and (d).

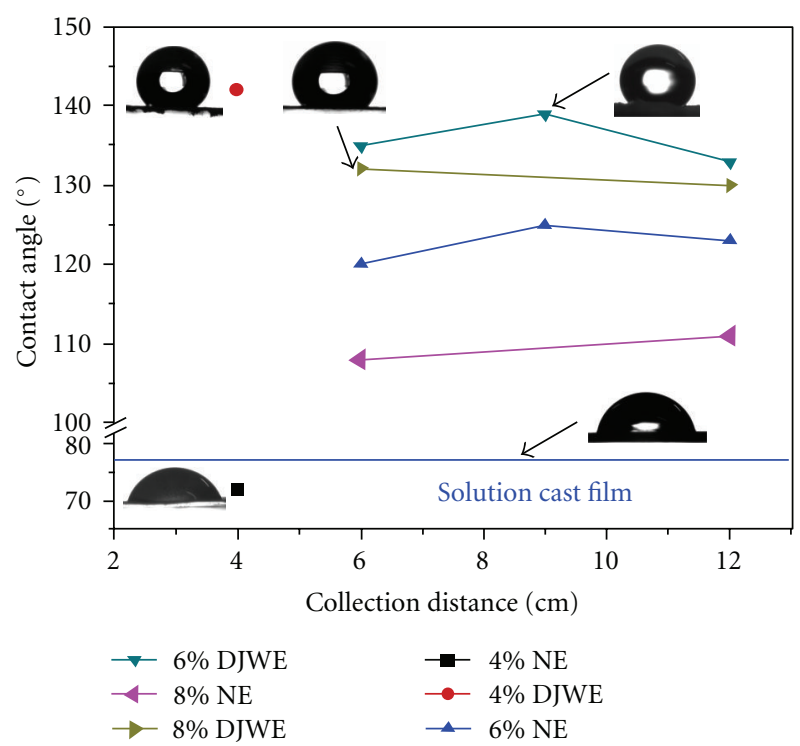

FIGURE 6: Water contact angle for electrospun mats prepared by normal electrospinning (NE) and dry-jet-wet-electrospinning (DJWE) at various distances.

held more air, and therefore were more hydrophobic than that from $4 \mathrm{wt} \%$ solution. And the beads from DJWE mats were beanpod-like or spindle-like, so the hydrophobicity was lower than that from $4 \mathrm{wt} \%$ solution. Both mats from NE

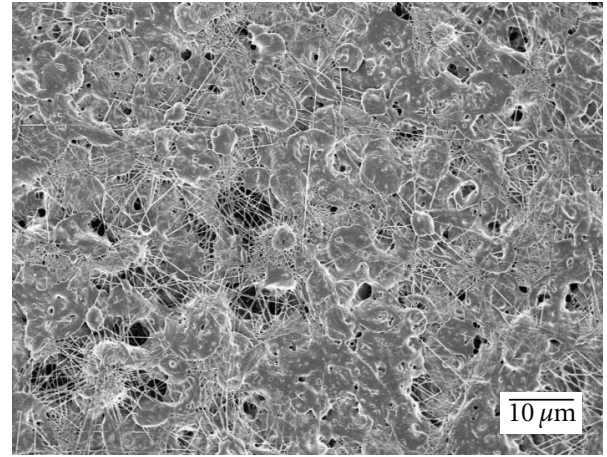

Figure 7: Electrospun mats from $4 \mathrm{wt} \%$ solution by normal electrospinning with collection distance of $4 \mathrm{~cm}$.

and DJWE had the highest hydrophobicity at the collection distance of $9 \mathrm{~cm}$. At this collection distance, the shape of beads was the nearest to sphere, and the bead ratio was the highest. The results implied that electrospun mats with higher bead density and rounder beads had higher porosity, which meant higher hydrophobicity.

The bead-free fibers prepared by the two methods also had similar tendency in wettability. The water contact angles of fiber mat prepared by DJWE were $130^{\circ}$, about $20^{\circ}$ higher than that prepared by normal electrospinning (both collected at $12 \mathrm{~cm}$ ). The increasing of contact angle might be the result of less coherence among fibers and consequently loose 
deposited structure. DJWE fiber mats collected at $6 \mathrm{~cm}$ were a little more hydrophobic than that collected at $12 \mathrm{~cm}$, which was because of the rough fiber surface.

\section{Conclusions}

Dry-jet-wet-electrospinning was carried out in this work to collect the electrospun jet at low distance to study the bead deformation mechanism of the PHBV fiber and the relationship between morphology and wettability. A beanpod-like bead which we named as primary bead was discovered and the formation of beaded PHBV fiber could be explained as follows: the jet was firstly stretched at the defects and formed the primary beads and fibers between adjacent beads. Then, if the fibers solidified and were stronger than the beads, the primary beads were further stretched and secondary beads which were common in electrospun fiber appeared. Otherwise, the fiber might be broken down by the electric field force. The bead-free fibers from DJWE had larger diameter but rougher surface than that from NE, due to the quick double-diffusion process.

The mats prepared by DJWE had obviously higher water contact angle than those by normal electrospinning, due to less adhesion and higher porosity. PHBV bead fiber mats with rounder beads and higher bead density were more hydrophobic. Therefore, the mat wettability was closely related to its surface morphology, and the hydrophobicity could be adjusted by the electrospun fiber morphology and the accumulation structures.

\section{Acknowledgments}

This work was jointly supported by the Nation Natural Science Foundation of China (50803012) and the National Science Fund for Distinguished Young Scholars (50925312).

\section{References}

[1] X. H. Qin and S. Y. Wang, "Filtration properties of electrospinning nanofibers," Journal of Applied Polymer Science, vol. 102, no. 2, pp. 1285-1290, 2006.

[2] C. H. Hung and W. W. F. Leung, "Filtration of nano-aerosol using nanofiber filter under low Peclet number and transitional flow regime," Separation and Purification Technology, vol. 79, no. 1, pp. 34-42, 2011.

[3] J. A. Matthews, G. E. Wnek, D. G. Simpson, and G. L. Bowlin, "Electrospinning of collagen nanofibers," Biomacromolecules, vol. 3, no. 2, pp. 232-238, 2002.

[4] F. Yang, R. Murugan, S. Wang, and S. Ramakrishna, "Electrospinning of nano/micro scale poly(l-lactic acid) aligned fibers and their potential in neural tissue engineering," Biomaterials, vol. 26, no. 15, pp. 2603-2610, 2005.

[5] W. J. Li, C. T. Laurencin, E. J. Caterson, R. S. Tuan, and F. K. Ko, "Electrospun nanofibrous structure: a novel scaffold for tissue engineering," Journal of Biomedical Materials Research, vol. 60, no. 4, pp. 613-621, 2002.

[6] L. Chen, L. Bromberg, H. Schreuder-Gibson, J. Walker, T. A. Hatton, and G. C. Rutledge, "Chemical protection fabrics via surface oximation of electrospun polyacrylonitrile fiber mats,"
Journal of Materials Chemistry, vol. 19, no. 16, pp. 2432-2438, 2009.

[7] L. Chen, L. Bromberg, J. A. Lee et al., "Multifunctional electrospun fabrics via layer-by-layer electrostatic assembly for chemical and biological protection," Chemistry of Materials, vol. 22, no. 4, pp. 1429-1436, 2010.

[8] X. J. Huang, A. G. Yu, J. Jiang, C. Pan, J. W. Qian, and Z. K. $\mathrm{Xu}$, "Surface modification of nanofibrous poly(acrylonitrileco-acrylic acid) membrane with biomacromolecules for lipase immobilization," Journal of Molecular Catalysis B, vol. 57, no. 1-4, pp. 250-256, 2009.

[9] J. Kim, J. W. Grate, and P. Wang, "Nanobiocatalysis and its potential applications," Trends in Biotechnology, vol. 26, no. 11, pp. 639-646, 2008.

[10] X. Wang, B. Ding, J. Yu, M. Wang, and F. Pan, "A highly sensitive humidity sensor based on a nanofibrous membrane coated quartz crystal microbalance," Nanotechnology, vol. 21, no. 5, Article ID 055502, 2010.

[11] C. Zhang, X. Wang, J. Lin, B. Ding, J. Yu, and N. Pan, "Nanoporous polystyrene fibers functionalized by polyethyleneimine for enhanced formaldehyde sensing," Sensors and Actuators B, vol. 152, no. 2, pp. 316-323, 2011.

[12] X. Wang, B. Ding, J. Yu, Y. Si, S. Yang, and G. Sun, "Electronetting: fabrication of two-dimensional nano-nets for highly sensitive trimethylamine sensing," Nanoscale, vol. 3, no. 3, pp. 911-915, 2011.

[13] H. Fong, I. Chun, and D. H. Reneker, "Beaded nanofibers formed during electrospinning," Polymer, vol. 40, no. 16, pp. 4585-4592, 1999.

[14] D. H. Reneker and A. L. Yarin, "Electrospinning jets and polymer nanofibers," Polymer, vol. 49, no. 10, pp. 2387-2425, 2008.

[15] M. M. Hohman, M. Shin, G. Rutledge, and M. P. Brenner, "Electrospinning and electrically forced jets. I. Stability theory," Physics of Fluids, vol. 13, no. 8, pp. 2201-2220, 2001.

[16] Y. M. Shin, M. M. Hohman, M. P. Brenner, and G. C. Rutledge, "Experimental characterization of electrospinning: the electrically forced jet and instabilities," Polymer, vol. 42, no. 25, pp. 9955-9967, 2001.

[17] G. Viswanathan, S. Murugesan, V. Pushparaj, O. Nalamasu, P. M. Ajayan, and R. J. Linhardt, "Preparation of biopolymer fibers by electrospinning from room temperature ionic liquids," Biomacromolecules, vol. 7, no. 2, pp. 415-418, 2006.

[18] S. Xu, J. Zhang, A. He, J. Li, H. Zhang, and C. C. Han, "Electrospinning of native cellulose from nonvolatile solvent system," Polymer, vol. 49, no. 12, pp. 2911-2917, 2008.

[19] E. Smit, U. Buttner, and R. D. Sanderson, "Continuous yarns from electrospun fibers," Polymer, vol. 46, no. 8, pp. 24192423, 2005.

[20] K. Acatay, E. Simsek, C. Ow-Yang, and Y. Z. Menceloglu, "Tunable, superhydrophobically stable polymeric surfaces by electrospinning," Angewandte Chemie-International Edition, vol. 43, no. 39, pp. 5210-5213, 2004.

[21] M. Ma, Y. Mao, M. Gupta, K. K. Gleason, and G. C. Rutledge, "Superhydrophobic fabrics produced by electrospinning and chemical vapor deposition," Macromolecules, vol. 38, no. 23, pp. 9742-9748, 2005.

[22] N. Q. Zhan, Y. X. Li, C. Q. Zhang et al., "A novel multinozzle electrospinning process for preparing superhydrophobic PS films with controllable bead-on-string/microfiber morphology," Journal of Colloid and Interface Science, vol. 345, no. 2, pp. 491-495, 2010.

[23] M. F. Zhu, W. W. Zuo, H. Yu, W. Yang, and Y. Chen, "Superhydrophobic surface directly created by electrospinning 
based on hydrophilic material," Journal of Materials Science, vol. 41, no. 12, pp. 3793-3797, 2006.

[24] Y. Il. Yoon, H. S. Moon, W. S. Lyoo, T. S. Lee, and W. H. Park, "Superhydrophobicity of PHBV fibrous surface with bead-onstring structure," Journal of Colloid and Interface Science, vol. 320, no. 1, pp. 91-95, 2008.

[25] K. Sombatmankhong, O. Suwantong, S. Waleetorncheepsawat, and P. Supaphol, "Electrospun fiber mats of poly(3hydroxybutyrate), poly(3-hydroxybutyrate-co-3-hydroxyvalerate), and their blends," Journal of Polymer Science B, vol. 44, no. 19, pp. 2923-2933, 2006.

[26] Y. I. Yoon, H. S. Moon, W. S. Lyoo, T. S. Lee, and W. H. Park, "Superhydrophobicity of PHBV fibrous surface with bead-onstring structure," Journal of Colloid and Interface Science, vol. 320, no. 1, pp. 91-95, 2008.

[27] W. Zuo, M. Zhu, W. Yang, H. Yu, Y. Chen, and Y. Zhang, "Experimental study on relationship between jet instability and formation of beaded fibers during electrospinning," Polymer Engineering and Science, vol. 45, no. 5, pp. 704-709, 2005.

[28] A. B. D. Cassie and S. Baxter, "Wettability of porous surfaces," Transactions of the Faraday Society, vol. 40, pp. 546-551, 1944. 

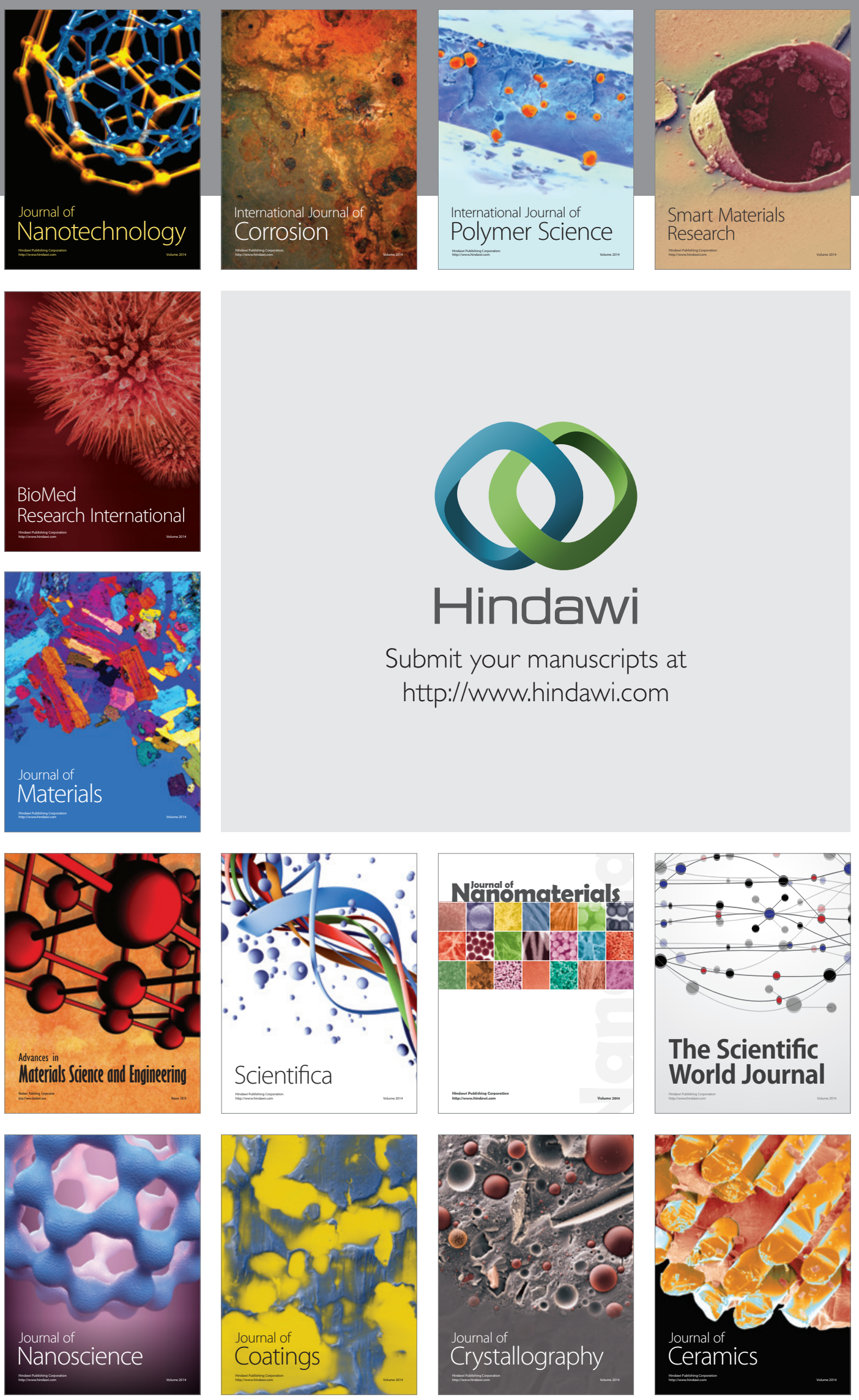

The Scientific World Journal

Submit your manuscripts at

http://www.hindawi.com

\section{World Journal}

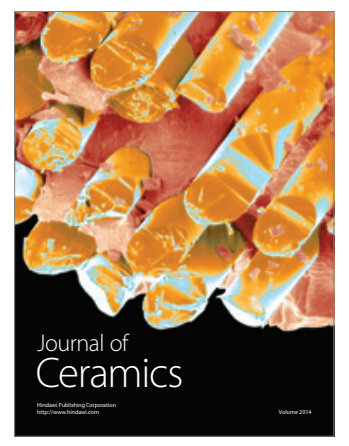

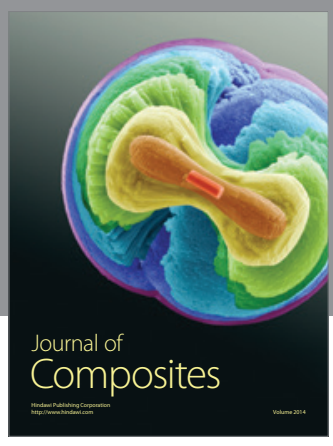
